\title{
ASSESSMENT OF COASTAL DEVELOPMENT IMPACTS ON CORAL ECOSYSTEMS IN NAIBAND BAY, THE PERSIAN GULF
}

\author{
Azadeh RAZAVI ARAB ${ }^{1}$, Afshin DANEHKAR ${ }^{2}$, S. Abbas HAGHSHENAS ${ }^{3}$, Gita B. EBRAHIMI ${ }^{4}$
}

This paper presents an application of Sediment Constituent Analysis (SCA) method to sediment samples taken particularly from the Naiband Bay, the Persian Gulf, to assess current conditions of the coral ecosystem in this area which has been affected by the ongoing developments in the neighboring South Pars Oil Field as well as construction a new port at Haleh in the south east corner of the bay.

\section{INTRODUCTION}

Human's life depends on ocean ecosystems for important and valuable goods and services; however, human use has also altered the oceans through direct and indirect means (Halpern et al. 2008). Coral ecosystems are very important for sustainable sediment supply to beaches and tourist. Moreover, corals are invaluable bio-indicators for extracting the history of pollutions and environmental changes. On the other hand, coral reefs are very sensitive to pollutions and suspended materials incorporated by coastal construction and development activities.

Naiband Bay represents a unique coastal system located on the middle part of the northern coastlines of the Persian Gulf. There has been extensive coral growth in different parts of the bay, especially over the southern part as well as near Assaluyeh Port in the north (Figure 1). The coral ecosystem in the area has been affected by developments in the neighboring South Pars Oil Field. The oil and gas development is still ongoing; moreover, a new port has been constructed at Haleh in the south east corner of the bay.

The present study aims to offer an assessment of coastal development impacts on the coral ecosystem in Naiband Bay based on constituent analysis of sediment samples taken from different parts of the bay. SCA is the method of assessing sediment samples under a microscope to determine the origin of constituent particles by visual inspection, and in some cases by the aid of stains.

Evidences regarding observing frequent big dead coral branches with few centimeters length on the beach together with the obtained results from the

\footnotetext{
1 Science and Research Branch, Islamic Azad University,Tehran,

IRAN,azadeh_razavi_1981@yahoo.com

2 University of Tehran, Tehran, IRAN, danehkar@ut.ac.ir

3 K. N. Toosi University of Technology, Tehran, IRAN, sahaghshenas@dena.kntu.ac.ir

4 Ports and Maritime Organization, Tehran, IRAN, gita_beir@yahoo.com
} 
performed constituent analysis reveal that coral reefs are deteriorating in the area, especially after Haleh Port construction. Some recommendations, hence, are proposed to mitigate the bad impacts incorporated by the coastal in Naiband Bay.

\section{SITE DESCRIPTION}

Naiband Bay, which is located about $400 \mathrm{~km}$ west of the Homuz Strait, has been formed in a $5 \mathrm{~km}$ syncline between two parallel mountain ranges; i.e. Madar and Assaluyeh anticlines. It has a $5 \mathrm{~km}$ long sandy beach with extensive coral growth at depths of 5 to $15 \mathrm{~m}$. These coral areas supply bio-clastic sediment to the beaches in this area. There is a unique mangrove forest at the north end of this bay (Figure 1), which all together make this area environmentally very important and also suitable as a tourist attraction. Gavbandi River pours into Naiband Bay at the south end of Naiband Beach. The southern shore of Naiband Bay features rock outcrops with pocket beaches in between. The bed in Naiband Bay is mostly covered by silt and sand exists on the south shore of the bay and along the Naiband Beach. The beach is made up of approximately $100 \%$ carbonate sand. The nearshore area is sheltered from wave action and is covered with live corals which produce carbonate sand. The coral cover is reported to be between $-2 \mathrm{~m}$ and $-10 \mathrm{~m}$ contours with $10 \%$ to $15 \%$ coral coverage (JWERC, 2009). A new port has been recently constructed at Haleh in the southeast corner of Naiband Bay. The construction process of the port was started in early 2010. The new breakwater shown in a recent Google satellite image (Figure 1) is constructed on edge of the area with significant coral growth and expected to block the flow of sediment towards the east. The sediment accretion on the western part of the port might be harmful for health of the coral ecosystem.

Evidences from observations in the site show a significant problem with coral ecosystem in the area. Several specimens of big dead coral branches could easily be observed on Naiband beach (Figure 2). Moreover, there is currently a light gray to white carbonate fillet beach northwest of the Assaluyeh Port. Until recently, Assaluyeh Port did not have a fillet beach. The port had suddenly begun to fill up with carbonate sediments 5 to6 years ago when a fillet beach was also created. Results of constituent analysis of sediment samples from the beach shows an estimation of coal fragments up to be $35 \%$ coral, which is too high. Big dead coral branches could be easily found in the lower layers of the bed. The color of the surface sediment (a thin film of sediments) on the Naiband beach has turned to light grey. It reveals that the newly deposited sediments are very young. 


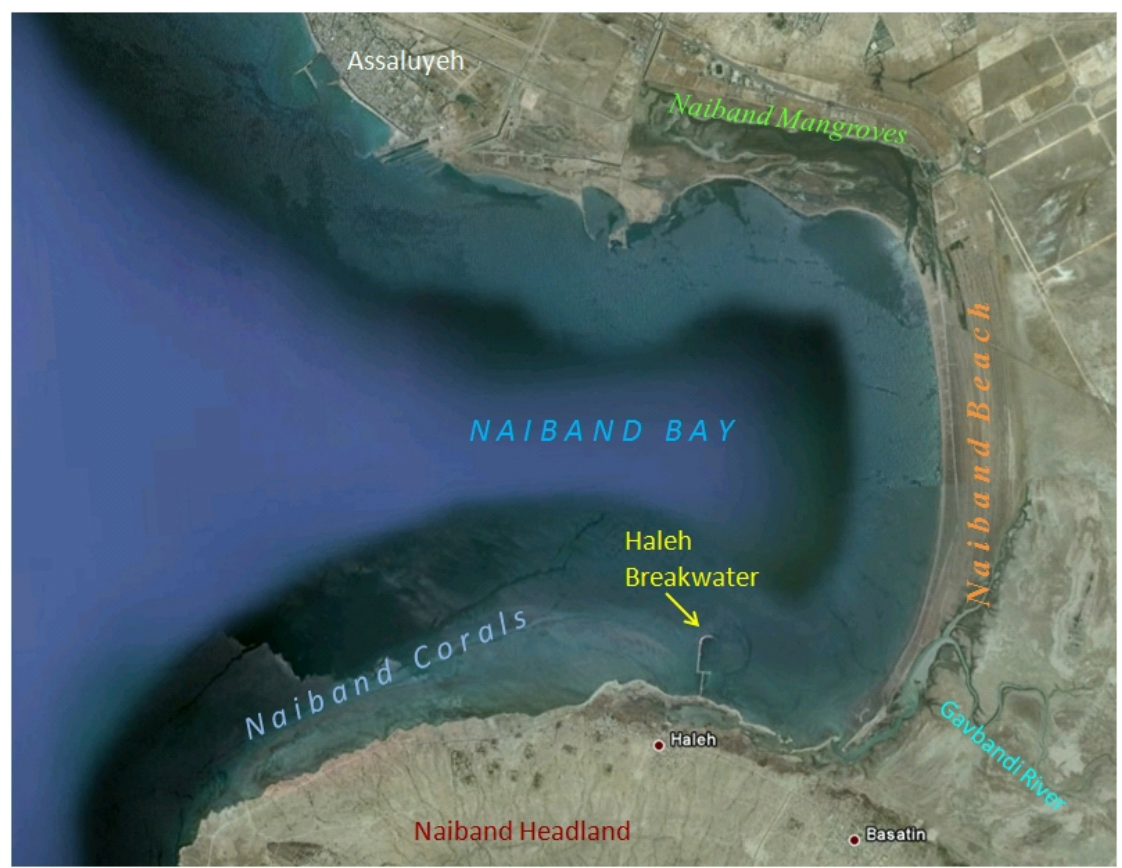

Figure 1. Google satellite image showing Naiband Bay

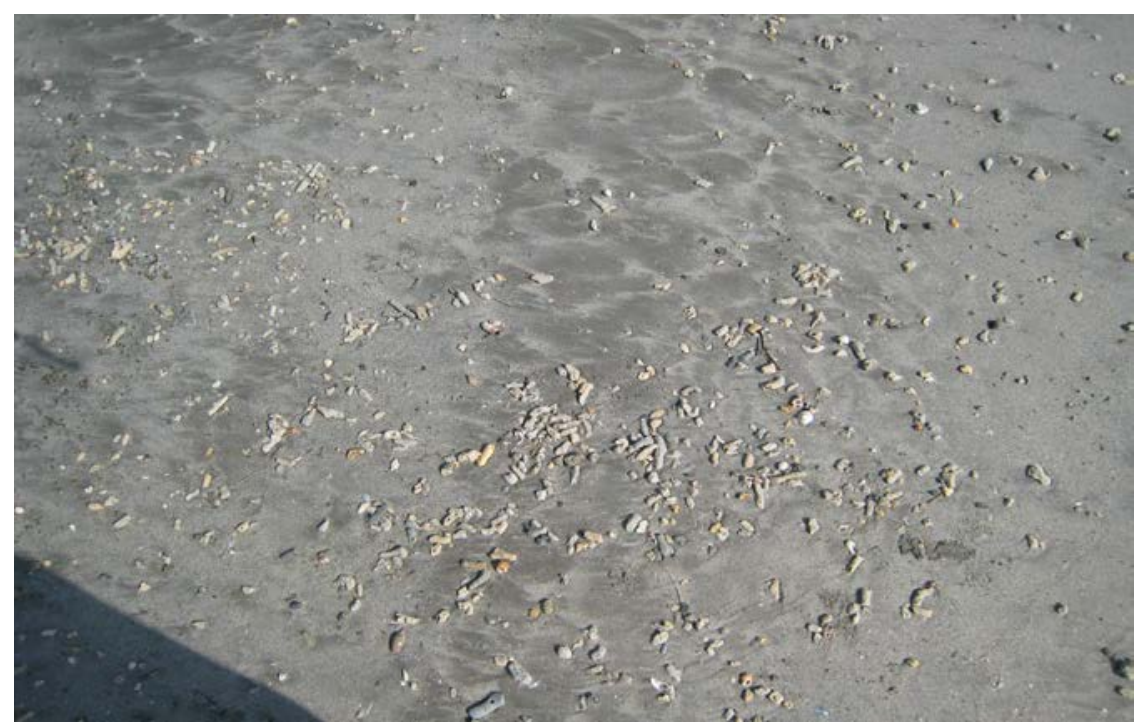

Figure 2. A general view of Naiband Beach with big dead coral branches on the surface 


\section{METHODOLOGY}

Eight sediment samples were taken from different parts of the bay as well as from areas near Assaluyeh and Nakhl-e-Taghi Ports. The sediments were analyzed for calculating coral fragments in the constituent sediments using a microscope with 40 times magnifying ability. The results are compared with arbitrary samples from other study, taken in 2009, searching for probable evidences regarding the changes in coral situations.

\section{RESULTS AND DISCUSSION}

Figure 3 shows results of the constituent sediment analysis in the bay. Coral grains (aragonite), usually angular fragments (initially), produced via predation, physical breakage, or death of the coral from disease, bleaching, and the like. Most "coral reef" sediments contain only a small amount of coral, about $5 \%$ to $10 \%$. The coral is the framework, and spikes in abundance are a sign of problems. Coral grains are resistant to physical breakdown. They may be recognized by their retention of the original coral architecture. Figure 3 shows results of the constituent sediment analysis in the bay. As it is in Figure 3, the percentage of coral grains in the constituent sediments all over the bay is higher than $20 \%$ with a single exception. Figure 4 presents changes in the percentage coral constituents in the Naiband Bay sediments between 2009 and 2011. As it is observed, coral constituent percentage has been increased all over the study domain. Figure 5 presents a comparison between constituent sediment analysis in a location east of Haleh Port before and after the construction. As it is observed, the percentage of coral grains has increased for $10 \%$. Grey young coral grains can be frequently observed in the sediment samples through the microscope. Moreover, the percentage of angular coral grains in the new sample is $80 \%$, while it is estimated $60 \%$ for the old one. This can be assumed as an approving evidence for the bad effects of Haleh Port construction process on the neighboring coral ecosystem. For mitigation of the bad effects two recommendations are presented here; 1) using rock fill material with fine material as less as possible and bypassing sediments over newly constructed breakwater in Haleh. 


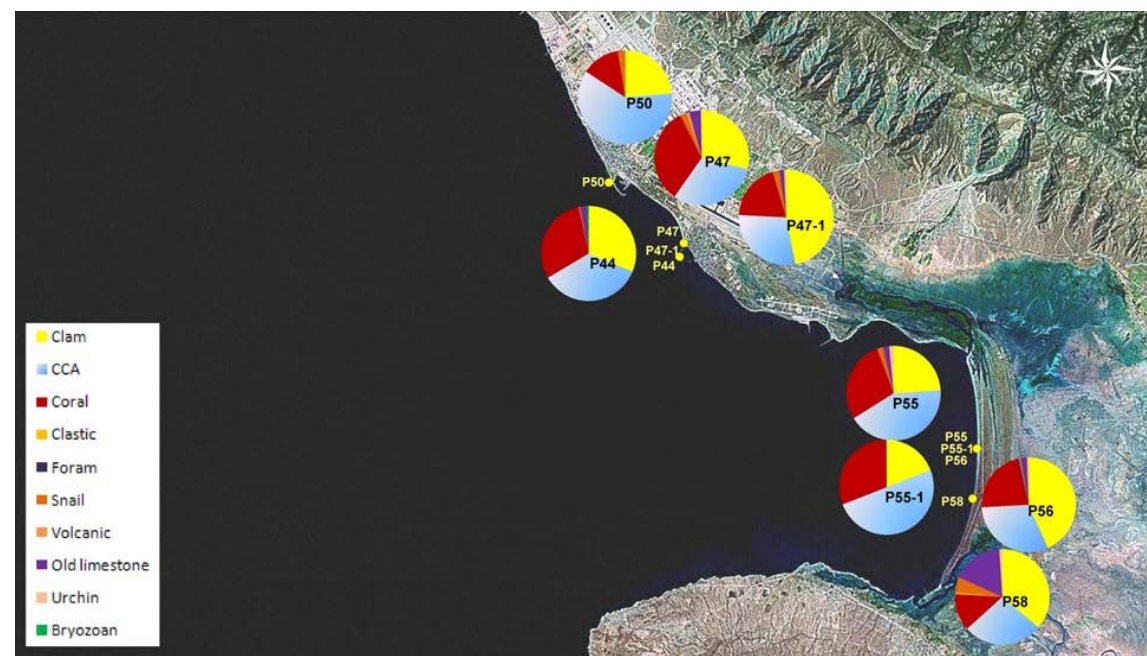

Figure 3. Results of constituent sediment analysis in the Naiband Bay

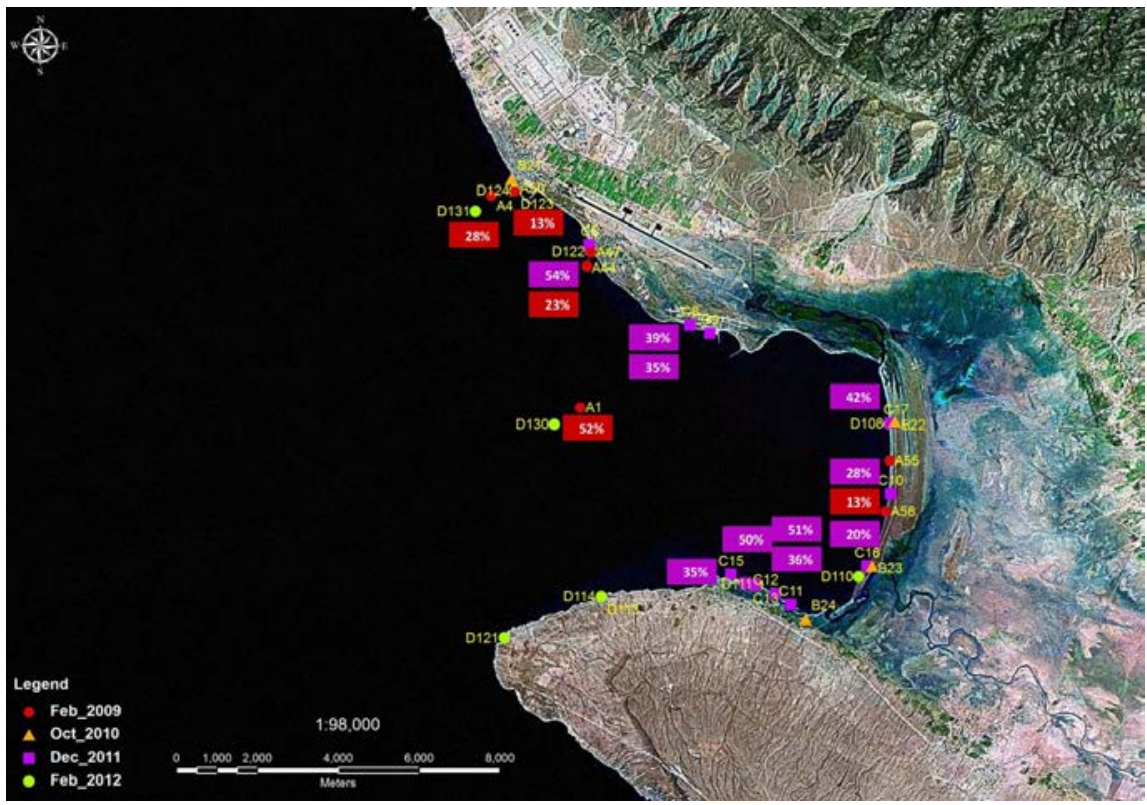

Figure 5. Changes in the Percentage coral constituents in the Naiband Bay sediments between 2009 and 2011 


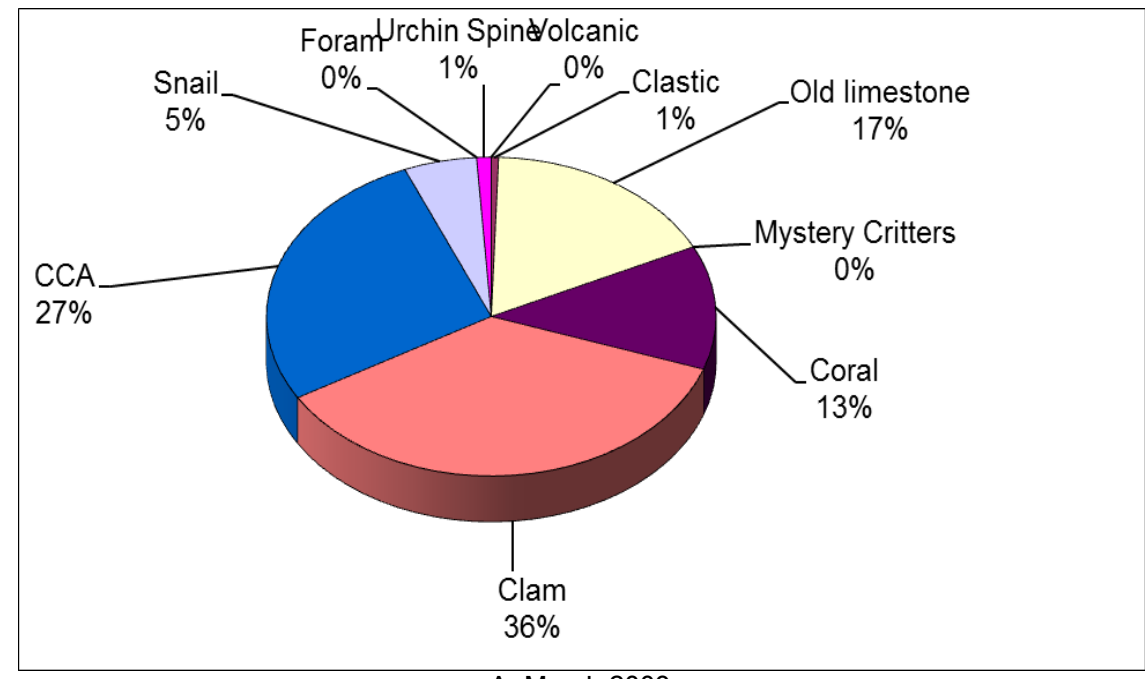

A: March 2009

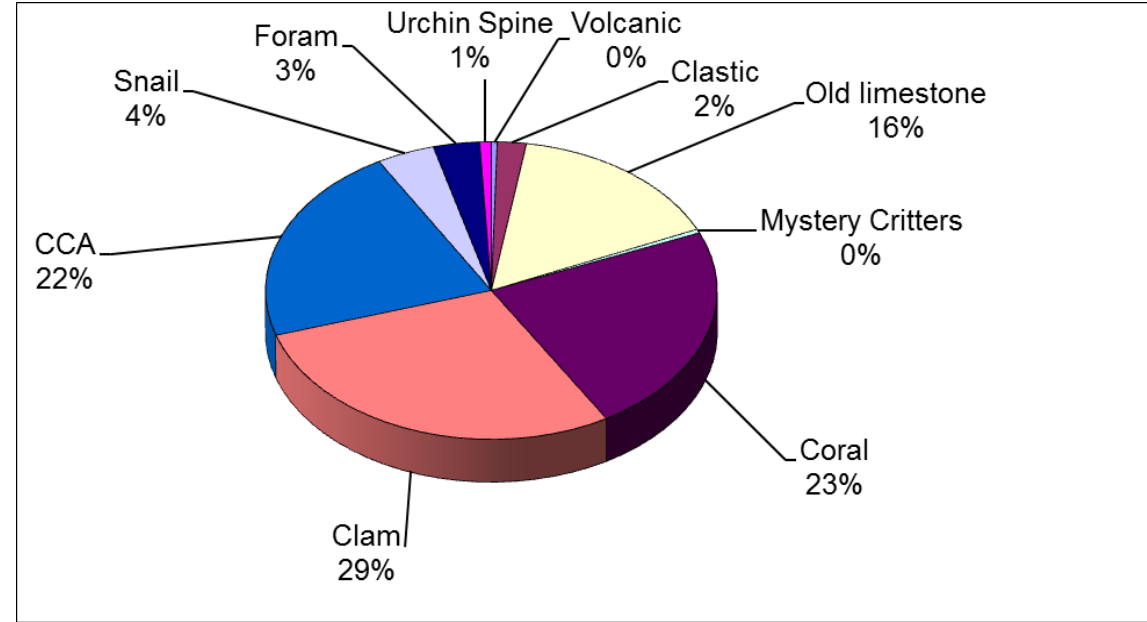

B: January 2011

Figure 4. Comparison between constituents sediments in two samples taken from an area west of haleh port in 2009 and 2011 


\section{REFERNCES}

B. S. Halpern, Walbridge, S., Selkoe, K. A., Kappel, C. V., Micheli, M., D’Agrosa, C., Bruno, J. F., Casey, K. S., Ebert, C., Helen E. Fox, H. E., Fujita, R., Heinemann, D., Lenihan,10 Elizabeth M. P. Madin, Perry, M. T., Selig, E. R., Spalding, M., Steneck, Watson, R. (2008). A Global Map of Human Impact on Marine Ecosystems, Science 319, 948 (2008); DOI: 10.1126/science.1149345.

Baird and JWERC (2009). Site Visit and Preliminary Geomorphic Assessment, Naiband Bay to Dayyer, report submitted to PMO. 
KEYWORDS - ICCE 2012

Paper Title:

Assessment of Coastal Development Impacts on Coral Ecosystems in Naiband Bay, the Persian Gulf

Authors: Azadeh RAZAVI ARAB

1, Afshin DANEHKAR ${ }^{2}$, S. Abbas HAGHSHENAS ${ }^{3}$, Gita B. EBRAHIMI ${ }^{4}$

\author{
Abstract number: 1131 \\ Persian Gulf \\ Coral Ecosystems \\ Sediment Constituent Analysis \\ Naiband Bay
}

\footnotetext{
${ }^{1}$ Science and Research Branch, Islamic Azad University,Tehran, IRAN,azadeh_razavi_1981@yahoo.com

2 University of Tehran, Tehran, IRAN, danehkar@ut.ac.ir

3 K. N. Toosi University of Technology, Tehran, IRAN, sahaghshenas@dena.kntu.ac.ir

4 Ports and Maritime Organization, Tehran, IRAN, gita_beir@yahoo.com
} 